\title{
PERFIL PEPTÍDICO DE HIDROLISADOS PROTEICOS DA FARINHA DE TRIGO ${ }^{1}$
}

\author{
Raquel Linhares Carreira ${ }^{2}$, Viviane Dias Medeiros Silva², \\ Letícia Gonçalves Lima², Harriman Aley Morais ${ }^{3}$, Marialice Pinto Coelho Silvestre ${ }^{2}$
}

\begin{abstract}
PEPTIDE PROFILE OF PROTEIN

HYDROLYSATES FROM WHEAT FLOUR

Protein hydrolysates have been increasingly used in specific formulations. This study aimed to obtain protein hydrolysates from wheat flour with appropriate peptide profile, from a nutritional point of view, i.e., containing high di-tripeptide and free amino acid contents, as well as low amounts of large peptides. Different hydrolytic conditions and sample treatments were tested, with the successive association of a commercial pancreatin and a raw enzymatic extract from the pineapple skin (RE). The order of enzyme addition, reaction temperature, enzyme:substrate ratio (E:S), and the effect of homogenization with ultra-turrax were evaluated, aiming the cost reduction on a large scale process. The peptide profile was evaluated by using a fractionation method, with size-exclusion-HPLC, followed by a Corrected Fraction Area method, for quantifying peptides and free amino acids. The best peptide profile was found for the hydrolysate obtained when pancreatin $(E: S=4: 100)$ acted firstly for 3 hours and 30 minutes, followed by RE $(E: S=10: 100)$, for 1 hour and 30 minutes, at optimal $\mathrm{pH}$ and temperature conditions of each enzyme, reaching higher di-tripeptide contents (16,98\%), one of the highest free amino acids contents $(42,70 \%)$, and the lowest large peptides content $(13,09 \%)$. The use of ultra-turrax had no effect on the peptide profile.
\end{abstract}

KEY-WORDS: Proteinase; agricultural residue; pineapple skin.

\section{INTRODUÇÃO}

A utilização de hidrolisados proteicos, em formulações específicas, é uma área de crescente interesse. Estes hidrolisados vêm sendo empregados na fabricação de alimentos especiais, para diversos grupos, tais como recém-nascidos prematuros, crianças com diarreia, gastroenterite, má-absorção e fenilcetonúria e pessoas com alergia a proteínas (Frei-

\section{RESUMO}

A utilização de hidrolisados proteicos, em formulações específicas, é uma área de crescente interesse. O objetivo deste trabalho consistiu na obtenção de hidrolisados proteicos de farinha de trigo com perfil peptídico adequado, do ponto de vista nutricional, ou seja, contendo elevado teor de di-tripeptídeos e aminoácidos livres e reduzida quantidade de grandes peptídeos. Foram avaliadas diferentes condições hidrolíticas e de tratamento da amostra, empregando-se a associação sucessiva de uma pancreatina comercial e de um extrato enzimático bruto da casca de abacaxi (EB). Avaliou-se a ordem de adição das enzimas, temperatura de reação, relação enzima:substrato (E:S) e o efeito da homogeneização com ultraturrax, visando à redução de custos para adaptação em larga escala. A análise do perfil peptídico foi realizada pelo fracionamento, por cromatografia líquida de alta eficiência de exclusão molecular, seguido pela quantificação dos peptídeos e aminoácidos livres, pelo método da Área Corrigida da Fração. O melhor perfil peptídico foi encontrado para o hidrolisado obtido quando a pancreatina $(\mathrm{E}: \mathrm{S}=4: 100)$ atuou primeiro por 3 horas e 30 minutos, seguida da ação do $\mathrm{EB}(\mathrm{E}: \mathrm{S}=10: 100)$, durante 1 hora e 30 minutos, nas condições ótimas de $\mathrm{pH}$ e temperatura de cada enzima, promovendo, assim, maior quantidade de di-tripeptídeos (16,98\%), um dos maiores teores de aminoácidos livres (42,70\%) e o menor conteúdo de grandes peptídeos (13,09\%). Observou-se, ainda, que o emprego do ultraturrax não afetou o perfil peptídico.

PALAVRAS-CHAVE: Proteinase; resíduo agrícola; casca de abacaxi.

tas et al. 1993, Akyiama et al. 2006). Além disto, estes preparados enzimáticos podem ser úteis na suplementação dietética de idosos, pacientes portadores de HIV/AIDS e na nutrição de esportistas, bem como em dietas para controle de peso (Frøkjaer 1994). Porém, a maior parte dos hidrolisados proteicos existentes no mercado nacional são obtidos a partir da caseína e do concentrado proteico do soro de leite, que são fontes proteicas importadas e de preço elevado. Por

1. Trabalho recebido em ago./2010 e aceito para publicação em out./2011 (nºgistro: PAT 10754/ DOI: 10.5216/pat.v41i4.10754).

2. Universidade Federal de Minas Gerais, Belo Horizonte, MG, Brasil.E-mails: quelecia@gmail.com, vivianedms@yahoo.com.br, letglima@yahoo.com.br,malice@ufmg.br.

3. Universidade Federal dos Vales do Jequitinhonha e Mucuri, Faculdade de Ciências Biológicas e da Saúde, Departamento de Ciências Básicas, Diamantina, MG, Brasil.E-mail: harriman.morais@ufvjm.edu.br. 
isto, o desenvolvimento de hidrolisados obtidos a partir de fontes proteicas de origem vegetal poderia representar uma alternativa viável para minimizar gastos na produção destes formulados (Rossi 2007).

O trigo, considerado essencial na alimentação humana, encontra-se entre os principais produtos agrícolas mundiais, apresentando safra anual próxima a 620 milhões de toneladas, em 2007 (Bordes et al. 2008), sendo empregado, principalmente, na produção de alimentos (67\%) e de ração animal (20\%) (Sayaslan et al. 2006).

Dentre todos os grãos de cereais, o trigo é o único panificável, devido à capacidade da sua farinha produzir uma massa que exibe propriedades reológicas (extensibilidade e elasticidade) adequadas à produção de pães, atributo, este, proporcionado pela presença das proteínas de reserva formadoras do glúten (gluteninas e gliadinas) (Manu \& Rao 2008). Este cereal é amplamente utilizado na alimentação humana, sob a forma de farinha, o que facilita o seu consumo e possibilita a melhor utilização de suas propriedades tecnológicas e nutricionais (Ortolan 2006). Pelo fato de a farinha de trigo já apresentar grande aceitação pelo consumidor, a introdução de hidrolisados proteicos de farinha de trigo de alto valor nutricional, em suplementos alimentares, causaria impacto positivo, pois complementaria um mercado deficiente em alimentos de elevado valor proteico (Miranda \& El-Dash 2002).

Uma das maneiras de se melhorar o valor nutricional da farinha de trigo consiste na hidrólise enzimática de suas proteínas, pois este processo dá origem a oligopeptídeos, especialmente di-tripeptídeos, que representam a forma proteica mais rapidamente utilizável pelo organismo (Grimble et al. 1986, Rérat 1993, Frenhani \& Burini 1999, Boza et al. 2000). Além disto, este processo hidrolítico, realizado em condições brandas e controladas, garante a manutenção da qualidade nutricional dos hidrolisados e a obtenção de um perfil peptídico definido para melhorar as propriedades funcionais ou nutricionais dos alimentos (Boza et al. 2000). Na forma hidrolisada, as proteínas da farinha de trigo poderiam ser utilizadas no desenvolvimento de suplementos alimentares de custo moderado e de bom valor nutricional.

No preparo de hidrolisados proteicos, utilizam-se, normalmente, proteases comerciais, que são produtos caros e, na maioria das vezes, importados. Por esta razão, no presente trabalho, testou-se a as- sociação de uma enzima comercial com um extrato enzimático bruto, obtido de um resíduo agroindustrial (casca de abacaxi), preparado em laboratório, visando a reduzir os custos do processo.

Considerando-se que o valor nutricional dos hidrolisados proteicos está associado ao seu teor de oligopeptídeos, especialmente di-tripeptídeos, Silvestre et al. (1994a) desenvolveram um método analítico, empregando uma coluna cromatográfica de exclusão molecular, contendo o complexo poli (2-hidroxietil-aspartamida)-sílica (PHEA), que lhes possibilitou fracionar e quantificar peptídeos com massas moleculares inferiores a $1.000 \mathrm{Da}$. Este método já foi utilizado na caracterização do perfil peptídico de hidrolisados enzimáticos obtidos de diversas fontes proteicas (Silvestre et al. 1994b, Morato et al. 2000, Carreira et al. 2004, Lopes et al. 2005, Morais et al. 2005, Soares et al. 2006, Biasutti et al. 2007, Lopes et al. 2007, Silva et al. 2007, Lopes et al. 2008).

O objetivo deste trabalho consistiu na avaliação de uma associação sucessiva de uma pancreatina comercial com o extrato enzimático bruto da casca de abacaxi (EB), por meio da avaliação de diferentes parâmetros hidrolíticos e tratamento da amostra, de forma a se obter hidrolisados proteicos de farinha de trigo contendo teores elevados de di-tripeptídeos e de aminoácidos livres, assim como quantidade reduzida de grandes peptídeos.

\section{MATERIAL E MÉTODOS}

O experimento foi realizado no Laboratório de Bromatologia da Faculdade de Farmácia da Universidade Federal de Minas Gerais (UFMG), em Belo Horizonte (MG), em 2008.

A farinha de trigo tipo I foi adquirida no comércio de Belo Horizonte (MG). A protease Protemax ${ }^{\circledR}$ 580 L (EC 3.4.21.14), uma serino-endopeptidase de origem bacteriana (cepa do Bacillus licheniformis, atividade $580 \mathrm{KDU} \mathrm{g}^{-1}$, estável em $\mathrm{pH}$ entre 7 e 10, com $\mathrm{pH}$ ótimo em 9,5 , temperatura ótima de $60^{\circ} \mathrm{C}$ e temperatura de inativação acima de $85^{\circ} \mathrm{C}$, por $10 \mathrm{mi}-$ nutos), foi adquirida da Prozyn (São Paulo, SP). A pancreatina (Corolase ${ }^{\circledR} \mathrm{PP}$ ) (complexo enzimático obtido do pâncreas - EC 3.4.21.4, constituído pelas serina-endopeptidases tripsina e quimotripsina e pelas metalo-exopeptidases carboxipeptidases A e B, atividade $200.000 \mathrm{LVE} \mathrm{g}^{-1}, \mathrm{pH}$ ótimo de 9 e temperatura ótima de $50^{\circ} \mathrm{C}$ ) foi adquirida da $\mathrm{AB}$ Enzymes Brasil Comercial Ltda. (Barueri, SP). 
O extrato enzimático bruto (EB) da casca do abacaxi (Ananas comosus) variedade Pérola foi preparado em laboratório. Para tal, as amostras foram, inicialmente, lavadas e descascadas e as porções de casca processadas em cutter e filtradas em gaze. Posteriormente, foram centrifugadas a $6.000 \mathrm{x} \mathrm{g}$, por 15 minutos, em centrífuga refrigerada a $4^{\circ} \mathrm{C}$. O sobrenadante foi adicionado de solução de ativadores EDTA $\left(4,0 \times 10^{-3} \mathrm{~mol} \mathrm{~L}^{-1}\right)$ e cisteína $\left(10^{-2} \mathrm{~mol} \mathrm{~L}^{-1}\right) \mathrm{e}$ armazenado em freezer, até o momento da análise.

Utilizou-se o liofilizador Freezone (modelo 77500, Labconco, Kansas City, MI, USA), cutter (Sire, modelo Super Cutter, São Paulo, Brasil), ultraturrax (IKA Labortechnix, T25 basic, Wilmington, EUA) e agitador magnético (Fisatom, modelo 752 A, São Paulo, SP, Brasil). O sistema de cromatografia líquida de alta eficiência (HPLC), usado no fracionamento dos hidrolisados proteicos, foi constituído por uma coluna cromatográfica poli-(2-hidroxietil-aspartamida)-silica (PHEA) de $250 \mathrm{~mm} x$ 9,4 mm, $5 \mu \mathrm{m}$ e $200 \AA$ (PolylC, Columbia, MD, EUA), uma bomba isocrática e um detector espectrofotométrico UV-VIS (série HP1100, Waldbronn, Alemanha), acoplado a um computador com software (HPChemstation, Avondale, EUA). A água usada no cromatógrafo foi purificada em Sistema de Purificação (Áries Vaponics, Rockland, EUA). Todos os reagentes utilizados eram de grau analítico.

Os hidrolisados proteicos foram preparados em duas etapas, sendo a primeira a extração enzimática das proteínas, seguindo-se o procedimento descrito por Capobiango et al. (2007), com algumas modificações. Sendo assim, a farinha de trigo foi suspensa em água destilada, na proporção de 1:5 $(\mathrm{p} / \mathrm{v})$, e o benzoato de sódio adicionado em quantidade necessária para uma concentração final de $0,1 \%(\mathrm{p} / \mathrm{v})$.
A suspensão foi agitada no ultraturrax (IKA Labortechnix, T25 basic, Wilmington, EUA), a $1.800 \mathrm{x}$ g, por 5 minutos, e a enzima, uma protease alcalina de Bacillus licheniformis, adicionada na relação E:S de 10:100, em sua condição ótima de $\mathrm{pH}$ $(9,5)$ e à temperatura de $55^{\circ} \mathrm{C}$.

$\mathrm{O}$ ajuste do $\mathrm{pH}$ foi realizado com solução de $\mathrm{NaOH}$, a $3 \mathrm{~mol} \mathrm{~L}^{-1}$, e a temperatura controlada em banho de vaselina líquida, sobre agitador magnético, ao passo que a extração enzimática foi realizada por 5 horas, com agitação constante. Após este tempo, a suspensão foi resfriada até $25^{\circ} \mathrm{C}$ e centrifugada, por 15 minutos, a $1.700 \mathrm{x} \mathrm{g}$.

O EPFT foi recolhido, separadamente, em um recipiente e o resíduo foi, então, lavado duas vezes, com água destilada, repetindo-se a etapa de centrifugação entre as lavagens e recolhendo-se sempre o EPFT no mesmo recipiente. O resíduo foi pesado e submetido a determinação do teor de proteína. A este procedimento, seguiu-se a hidrólise enzimática, empregando-se as condições hidrolíticas apresentadas na Tabela 1.

Assim, foi empregada a associação sucessiva da pancreatina comercial com o extrato enzimático bruto da casca de abacaxi (EB), estudando-se, também, outros parâmetros hidrolíticos, como a ordem de adição das enzimas (pancreatina + EB e EB + pancreatina), temperatura $\left(35^{\circ} \mathrm{C}, 40^{\circ} \mathrm{C}, 50^{\circ} \mathrm{C}\right.$ e $\left.70^{\circ} \mathrm{C}\right)$, relação enzima:substrato (E:S) $(2: 100,3: 100$ e 4:100, para a pancreatina), bem como o efeito do tratamento físico da amostra. Para todas as amostras analisadas, definiu-se o tempo total de 5 horas de reação.

$\mathrm{O}$ controle de $\mathrm{pH}$ foi realizado ajustando-se o pH dos extratos para os valores de 7 e 8 , com uma solução de $\mathrm{NaOH}$ ( $\left.3 \mathrm{~mol} \mathrm{~L}^{-1}\right)$, enquanto, para o ajuste de temperatura, foi empregado um termômetro de mercúrio imerso na solução do extrato proteico de fa-

Tabela 1. Variáveis empregadas no preparo dos hidrolisados proteicos da farinha de trigo (Belo Horizonte, MG, 2008).

\begin{tabular}{|c|c|c|c|c|c|c|}
\hline \multicolumn{7}{|c|}{ Parâmetros hidrolíticos } \\
\hline $\mathrm{H}^{1}$ & Protease & $\mathrm{E}: \mathrm{S}^{3}$ & $\mathrm{~T}^{4}\left({ }^{\circ} \mathrm{C}\right)$ & Tempo (h) & $\mathrm{pH}$ & $\mathrm{TE}^{5}$ \\
\hline $\mathrm{H} 1$ & $\mathrm{~EB}^{2}+$ pancreatina & $10: 100+4: 100$ & $70 / 50$ & $1 \mathrm{~h} 30 \mathrm{~min} . / 3 \mathrm{~h} 30 \mathrm{~min}$. & $8 / 7$ & Ausente \\
\hline $\mathrm{H} 2$ & Pancreatina $+\mathrm{EB}$ & $4: 100+10: 100$ & $50 / 70$ & $3 \mathrm{~h} 30 \mathrm{~min} . / 1 \mathrm{~h} 30 \mathrm{~min}$. & $7 / 8$ & Ausente \\
\hline $\mathrm{H3}$ & $\mathrm{EB}+$ pancreatina & $10: 100+4: 100$ & 35 & $1 \mathrm{~h} 30 \mathrm{~min} . / 3 \mathrm{~h} 30 \mathrm{~min}$. & 7 & Ausente \\
\hline H4 & $\mathrm{EB}+$ pancreatina & $10: 100+4: 100$ & 40 & $1 \mathrm{~h} 30 \mathrm{~min} . / 3 \mathrm{~h} 30 \mathrm{~min}$. & 7 & Ausente \\
\hline H5 & $\mathrm{EB}+$ pancreatina & $10: 100+4: 100$ & 50 & $1 \mathrm{~h} 30 \mathrm{~min} . / 3 \mathrm{~h} 30 \mathrm{~min}$. & 7 & Ausente \\
\hline H6 & $\mathrm{EB}+$ pancreatina & $10: 100+4: 100$ & 70 & $1 \mathrm{~h} 30 \mathrm{~min} . / 3 \mathrm{~h} 30 \mathrm{~min}$. & 7 & Ausente \\
\hline $\mathrm{H} 7$ & $\mathrm{~EB}+$ pancreatina & $10: 100+2: 100$ & 50 & $1 \mathrm{~h} 30 \mathrm{~min} . / 3 \mathrm{~h} 30 \mathrm{~min}$. & 7 & Ausente \\
\hline H8 & $\mathrm{EB}+$ pancreatina & $10: 100+3: 100$ & 50 & $1 \mathrm{~h} 30 \mathrm{~min} . / 3 \mathrm{~h} 30 \mathrm{~min}$. & 7 & Ausente \\
\hline H9 & $\mathrm{EB}+$ pancreatina & $10: 100+3: 100$ & 50 & $1 \mathrm{~h} 30 \mathrm{~min} . / 3 \mathrm{~h} 30 \mathrm{~min}$. & 7 & Ultraturrax \\
\hline
\end{tabular}

${ }^{1}$ Hidrolisados. ${ }^{2}$ Extrato enzimático bruto da casca de abacaxi. ${ }^{3}$ Relação enzima:substrato. ${ }^{4}$ Temperatura. ${ }^{5}$ Tratamento físico do extrato. 
rinha de trigo, que estava sendo hidrolisado, visando a atender as condições ótimas de ação das enzimas. Após o tempo total de hidrólise, as enzimas foram inativadas por aquecimento $\left(80^{\circ} \mathrm{C}\right.$, por 20 minutos), sendo as amostras liofilizadas e armazenadas em freezer, a $-4^{\circ} \mathrm{C}$, até o momento do uso.

Para caracterizar o perfil peptídico, foi realizado o fracionamento das amostras, de acordo com o tamanho da cadeia, empregando-se a cromatografia líquida de alta eficiência - exclusão molecular (SE-HPLC), em coluna PHEA (Silvestre et al. 1994a). Assim, os hidrolisados foram dissolvidos, à concentração de $1 \mathrm{~g} \%(\mathrm{p} / \mathrm{v})$, na fase móvel (ácido fórmico a $\left.0,05 \mathrm{~mol} \mathrm{~L}^{-1} ; \mathrm{pH} 2,5\right)$, e submetidos à cromatografia, à temperatura ambiente, sob condições isocráticas, em fluxo de $0,5 \mathrm{~mL}^{\text {minuto }}{ }^{-1}$, durante 35 minutos, injetando-se volume de $20 \mu \mathrm{L}$. A fase móvel foi filtrada em membrana de $0,45 \mu \mathrm{m}$ (Millipore Indústria e Comércio Ltda, São Paulo, SP, Brasil) e degaseificada imediatamente antes do uso.

Posteriormente, os peptídeos e aminoácidos livres presentes nos hidrolisados foram quantificados pelo método rápido da Área Corrigida da Fração (Silvestre et al. 1994b), no qual se realizou a multidetecção das frações a $230 \mathrm{~nm}, 280 \mathrm{~nm}$ e $300 \mathrm{~nm}$, para se eliminar a interferência causada pela absorção dos aminoácidos aromáticos. Traçou-se, então, uma curva padrão, relacionando a ACF, em função do teor de aminoácidos (Silvestre et al. 1994b, Morato et al. 2000, Carreira et al. 2004, Lopes et al. 2005, Morais et al. 2005, Soares et al. 2006, Lopes et al. 2007, Silva et al. 2007).

Todos os experimentos foram feitos em três repetições e as análises realizadas em triplicata. Os dados foram submetidos a análise de variância e, para avaliação das diferenças entre as médias dos teores de peptídeos e aminoácidos livres das frações cromatográficas dos hidrolisados do extrato proteico de farinha de trigo, foi utilizado o Teste de Duncan $(\mathrm{p} \leq 0,05)$ (Pimentel-Gomes 2000).

\section{RESULTADOS E DISCUSSÃO}

Os hidrolisados proteicos foram separados em quatro frações, de acordo com o tempo de eluição, sendo F1 de 11,5 a 16,0 minutos (grandes peptídeos, com mais de 7 resíduos de aminoácidos), F2 de 16,0 a 19,5 minutos (peptídeos médios, entre 4 e 7 resíduos), F3 de 19,5 a 20,5 minutos (di-tripeptídeos) e F4 de 20,5 a 32,0 minutos (aminoácidos livres). A técnica de SE-HPLC, utilizada no presente trabalho, permitiu a caracterização dos hidrolisados proteicos, especialmente com relação ao fracionamento de peptídeos com massas moleculares inferiores a 1.000 Da. Este resultado está de acordo com o apresentado por outros trabalhos que empregaram a mesma técnica, visando ao fracionamento de hidrolisados enzimáticos obtidos de diversas fontes proteicas, e em condições de hidrólise variadas, dentre os quais destacam-se os realizados com caseína (Morato et al. 2000, Carreira et al. 2004, Morais et al. 2005), arroz (Lopes et al. 2008), leite desnatado (Lopes et al. 2005, Soares et al. 2006 e 2007), soro de leite (Silva et al. 2007, Biasutti et al. 2008, Souza et al. 2008) e concentrado proteico de soro de leite (Afonso et al. 2008 e 2009).

Na literatura, são encontradas diversas técnicas para o fracionamento dos peptídeos de hidrolisados proteicos, como, por exemplo, a cromatografia de exclusão molecular (SEC) e a cromatografia líquida de alta velocidade, com eletrospray acoplado ao espectrômetro de massa (Li-Jun et al. 2008), HPLC capilar (Ito et al. 2005), HPLC de fase reversa (Nogueira et al. 2005), HPLC de exclusão molecular (SE-HPLC), empregando-se coluna TSK G-2000 SW (6 cm x 7,5 cm) (Lemieux et al. 1991) e coluna Superose - 12HR 10/30 (Golovchenko et al. 1992, Visser et al. 1992), cromatografia rápida de fase líquida de proteína (Je et al. 2007) e foco isoelétrico em fase líquida (Saint-Sauveur et al. 2008).

Entretanto, ao contrário da técnica aqui utilizada, a maioria destes métodos apresenta uma série de inconvenientes. Assim, Lemieux et al. (1991), empregando a SE-HPLC com uma coluna TSK G-2000 SW, relataram a dificuldade de se separar os peptídeos de acordo com o tamanho da cadeia, tendo observado uma superposição de compostos com pesos moleculares diferentes. De acordo com Nogueira et al. (2005), na HPLC de fase reversa, há sobreposição de peptídeos e impureza nos picos. Além disto, também pode ocorrer sobrecarga de peptídeos básicos, tanto na HPLC de fase reversa quanto na HPLC capilar (McCalley 2004). Golovchenko et al. (1992) e Visser et al. (1992), também utilizando SE-HPLC, porém com uma coluna Superose-12HR 10/30, verificaram a ocorrência de interações eletrostáticas e/ou hidrofóbicas entre os solutos e a fase estacionária.

Alguns autores têm relatado o emprego da SE-HPLC, para a caracterização do perfil peptídico dos hidrolisados de glúten do trigo (Kong et al. 2007, Wang et al. 2007). Entretanto, em nenhum destes 
trabalhos foi possível separar os di-tripeptídeos dos peptídeos maiores. Assim, Kong et al. (2007), ao avaliarem a distribuição da massa molecular dos peptídeos obtidos da hidrólise do glúten do trigo, sob ação das enzimas proteolíticas alcalase (Bacillus licheniformis) e Neutrase (Bacillus amyloliquefaciens), empregando a SE-HPLC com a coluna Sephadex G-15, observaram apenas que os peptídeos apresentavam massa molecular inferior a 1.355 Da, não sendo avaliado, em separado, o conteúdo de di-tripeptídeos.

De forma semelhante, Wang et al. (2007) caracterizaram o perfil peptídico dos hidrolisados de glúten do trigo obtidos com o uso de uma papaína. $\mathrm{O}$ método analítico utilizado neste estudo (SE-HPLC, com a coluna BioSepSec-4000) separou os peptídeos obtidos nas seguintes frações: maiores que 15.000 Da, entre 15.000 Da e 10.000 Da, entre 5.000 Da e 10.000 Da e menores que 5.000 Da.

Outros autores têm empregado a técnica do fracionamento por SE-HPLC, para avaliar o perfil peptídico de hidrolisados proteicos de farinha de trigo. Assim, Akiyama et al. (2006) empregaram este método cromatográfico com a coluna Superdex ${ }^{\mathrm{TM}}$ Peptide HR, com o intuito de separar as frações dos hidrolisados ácido e enzimático. Entretanto, este método não foi capaz de fracionar os peptídeos de acordo com o tamanho da cadeia, especialmente os pequenos peptídeos. Segundo os autores, apenas a faixa de massa molecular foi evidenciada, sendo que, no hidrolisado preparado sob a ação de protease, predominaram os peptídeos com massa molecular superior a 1.050.000 Da, enquanto os peptídeos obtidos no hidrolisado ácido ficaram na faixa de 500.000-1.050.000 Da.

Manu \& Rao (2008) fracionaram, por SE-HPLC, com a coluna Biosep-SEC-S-4000, os extratos proteicos obtidos a partir de diferentes cultivares de farinha de trigo, obtendo as frações F1 (> 130.000 Da), F2 (80.000-130.000 Da), F3 $(10.000-80.000 \mathrm{Da})$ e F4 $(<5.000 \mathrm{Da})$, sendo estes valores superiores aos determinados no presente estudo. Da mesma maneira, Kammoun et al. (2003) utilizaram a SE-HPLC e a coluna Shodex KW 802.5, para caracterizar o perfil peptídico do hidrolisado de farinha de trigo obtido pela ação da enzima Neutrase (endoprotease de Bacillus subtilis), obtendo, também, 4 frações: F1 (0-1.000 Da), F2 (1.000-2.000 Da), F3 (2.000-3.000 Da) e F4 (> 3.000 Da), estando apenas a F1 dentro da faixa de massa molecular de principal interesse ao presente trabalho.

Não houve grande variação nos perfis peptídicos dos hidrolisados proteicos da farinha de trigo (Tabela 2). Acrescenta-se, ainda, que os perfis peptídicos obtidos para todos os hidrolisados podem ser considerados adequados, do ponto de vista nutricional, uma vez que, em diversos trabalhos do mesmo grupo de pesquisa em que foram testadas várias fontes proteicas e inúmeras condições hidrolíticas, ficou evidenciada a dificuldade de se obter teores de di-tripeptídeos acima de 10\%, aminoácidos livres acima de $30 \%$ e grandes peptídeos abaixo de 25\% (Morato et al. 2000, Carreira et al. 2004, Lopes et al. 2005, Morais et al. 2005, Soares et al. 2006, Biasutti et al. 2007, Silva et al. 2007, Lopes et al. 2008).

Tabela 2. Teor de peptídeos e de aminoácidos livres nas frações cromatográficas dos hidrolisados do extrato proteico de farinha de trigo (Belo Horizonte, MG, 2008).

\begin{tabular}{|c|c|c|c|c|}
\hline \multirow[t]{2}{*}{ Hidrolisado } & $\begin{array}{c}\mathrm{F} 1 \\
\left(>7 \text { resíduos de } \mathrm{AA}^{1}\right)\end{array}$ & $\begin{array}{c}\mathrm{F} 2 \\
(4-7 \text { resíduos de AA) }\end{array}$ & $\begin{array}{c}\text { F3 } \\
\text { (di-tripeptídeos) }\end{array}$ & $\begin{array}{c}\mathrm{F} 4 \\
\text { (AA livres) }\end{array}$ \\
\hline & \multicolumn{4}{|c|}{ Fração $(\% \mathrm{nmol})$} \\
\hline H1 & $15,42 \mathrm{Cd}$ & $32,96 \mathrm{Ba}$ & $12,03 \mathrm{Ce}$ & $39,58 \mathrm{Aab}$ \\
\hline $\mathrm{H} 2$ & $13,09 \mathrm{De}$ & $27,23 \mathrm{Bc}$ & $16,98 \mathrm{Ca}$ & $42,70 \mathrm{Aa}$ \\
\hline $\mathrm{H} 3$ & $22,61 \mathrm{Ca}$ & $30,68 \mathrm{Bab}$ & 13,55 Dcde & $34,15 \mathrm{Abc}$ \\
\hline $\mathrm{H} 4$ & $17,89 \mathrm{Cc}$ & $31,24 \mathrm{Bab}$ & $15,16 \mathrm{Cabc}$ & $35,71 \mathrm{Abc}$ \\
\hline H5 & $15,85 \mathrm{Cd}$ & $29,95 \mathrm{Babc}$ & $15,52 \mathrm{Cabc}$ & $38,68 \mathrm{Aab}$ \\
\hline H6 & $20,08 \mathrm{Bb}$ & $32,72 \mathrm{Aa}$ & $14,64 \mathrm{Cbcd}$ & $32,56 \mathrm{Ac}$ \\
\hline $\mathrm{H} 7$ & $23,06 \mathrm{Ca}$ & $29,21 \mathrm{Bbc}$ & 12,85 Dde & $34,89 \mathrm{Abc}$ \\
\hline $\mathrm{H} 8$ & $18,39 \mathrm{Cbc}$ & $29,18 \mathrm{Bbc}$ & 13,80 Dbcde & $38,62 \mathrm{Aab}$ \\
\hline $\mathrm{H} 9$ & $18,47 \mathrm{Cbc}$ & 30,37 Babc & $15,95 \mathrm{Cab}$ & $35,22 \mathrm{Abc}$ \\
\hline
\end{tabular}


Para escolha do hidrolisado que apresentou o melhor perfil peptídico, as ponderações de alguns autores devem ser consideradas. Assim, segundo Frenhani \& Burini (1999), durante o metabolismo de proteínas, o primeiro estágio de hidrólise leva à formação de oligopeptídeos contendo de 2 a 6 resíduos de aminoácidos e aminoácidos livres. Estes peptídeos são, então, quebrados em di-tripeptídeos e, finalmente, as proteínas são absorvidas nesta forma e na de aminoácidos livres. Ainda de acordo com estes mesmos autores, os di-tripeptídeos são mais eficientemente absorvidos que os aminoácidos livres, os quais, por sua vez, são melhor absorvidos que os tetra-peptídeos ou peptídeos superiores. Em quantidades equivalentes de di-tripeptídeos e misturas de aminoácidos livres, os primeiros apresentam velocidade de absorção aproximadamente 10 vezes superior. González-Tello et al. (1994) também relataram as vantagens dos di-tripeptídeos sobre os aminoácidos livres, por apresentarem maior velocidade de absorção.

Desta maneira, concluiu-se que o melhor perfil peptídico, do ponto de vista nutricional, dentre todos os hidrolisados analisados, foi o obtido para o hidrolisado $\mathrm{H} 2$, que apresentou a maior quantidade de di-tripeptídeos (16,98\%), um dos maiores teores de aminoácidos livres $(42,70 \%)$ e o menor teor de grandes peptídeos $(13,09 \%)$. Por outro lado, os perfis peptídicos mais desfavoráveis foram obtidos para os hidrolisado $\mathrm{H} 3$ e H7, uma vez que apresentaram um dos menores teores de di-tripeptídeos (13,55\% e $12,85 \%$, respectivamente) e um dos maiores teores de grandes peptídeos $(22,61 \%$ e $23,06 \%$, respectivamente).

Para a análise de alguns parâmetros utilizados neste trabalho (E:S, temperatura e emprego do ultraturrax), levou-se em consideração a redução de custos do processo para adaptação à produção em larga escala. Assim, a redução da relação E:S está associada ao emprego de menor quantidade de enzima necessária à hidrólise, e a diminuição da temperatura de reação está relacionada à menor probabilidade de formação de produtos de degradação, além de menor consumo de energia, e à eliminação da etapa operacional do ultraturrax, que contribui para a redução dos custos do processo.

No estudo da associação sucessiva da pancreatina com o EB, observou-se que a ordem de adição das enzimas interferiu no perfil cromatográfico dos hidrolisados obtidos. Assim, dentre as condições estudadas (H1 - EB + pancreatina e
H2 - pancreatina + EB), a melhor distribuição de peptídeos, de acordo com o tamanho da cadeia, foi obtida quando a pancreatina atuou primeiro, uma vez que produziu maior teor de di-tripeptídeos (H2: $16,98 \%$ e H1: $12,03 \%$ ) e menor teor de grandes peptídeos (H2: 13,09\% e H1: 15,42\%). Por outro lado, não houve diferença significativa entre os teores de aminoácidos livres (39,58\% e 42,70\%, para $\mathrm{H} 1$ e H2, respectivamente). Ressalta-se que esta avaliação foi realizada apenas com estas amostras, uma vez que o presente trabalho representa parte de uma linha de pesquisa, cuja meta final está relacionada à obtenção de diversos alimentos com teor reduzido de fenilalanina. Assim sendo, em trabalho anterior desta mesma equipe (Carreira et al. 2010), foi mostrado que estas condições de reação (EB + pancreatina) levaram a uma maior remoção deste aminoácido. Acrescenta-se, ainda, que as amostras de $\mathrm{H} 3$ a $\mathrm{H} 6$ foram preparadas seguindo-se as melhores condições obtidas ao se preparar H1 e H2, variando-se, apenas, a temperatura de reação.

Considerando-se que tanto a pancreatina como o EB são constituídos de misturas de várias enzimas proteolíticas (exopeptidases), provavelmente, no início da reação, predominou a ação das endopeptidases sobre as exopeptidases da pancreatina, liberando peptídeos de tamanhos variados. Em seguida, a ação das endopeptidases do EB foi, igualmente, mais eficiente do que a das exopeptidases, atuando, assim, sobre os peptídeos liberados pela pancreatina, reduzindo o seu tamanho.

Não foram encontrados, na literatura, relatos abordando o efeito da ordem de adição das enzimas sobre o perfil peptídico de hidrolisados proteicos da farinha de trigo ou de outros cereais.

A influência da temperatura sobre o perfil peptídico dos hidrolisados enzimáticos da farinha de trigo pode ser avaliada comparando-se os hidrolisados $\mathrm{H} 3\left(35^{\circ} \mathrm{C}\right), \mathrm{H} 4\left(40^{\circ} \mathrm{C}\right), \mathrm{H} 5\left(50^{\circ} \mathrm{C}\right)$ e $\mathrm{H} 6$ $\left(70^{\circ} \mathrm{C}\right)$. Observa-se (Tabela 2) que o melhor perfil peptídico, do ponto de vista nutricional, foi obtido a $50^{\circ} \mathrm{C}$. Além disto, o emprego vantajoso de uma menor temperatura ocorreu ao se compararem os valores de $50^{\circ} \mathrm{C}(\mathrm{H} 5)$ e $70^{\circ} \mathrm{C}(\mathrm{H} 6)$, pois, apesar de não ter sido observada diferença significativa, em relação aos teores de di-tripeptídeos, o emprego da temperatura mais baixa levou à obtenção de teores mais elevados de aminoácidos livres $(38,68 \%$, em H5, e 32,56\%, em H6) e de menor quantidade de grandes peptídeos $(15,85 \%$ e $20,08 \%$, para H5 e H6, respectivamente). 
Este resultado poderia ser explicado, pelo menos em parte, por ser $50^{\circ} \mathrm{C}$ a temperatura ótima de ação da pancreatina e, portanto, a hidrólise a $50^{\circ} \mathrm{C}$ intensifica sua atividade proteolítica, ao passo que o emprego de elevadas temperaturas ocasionaria a formação de estados de transição de energia, sendo este processo acompanhado de uma pequena, mas significativa, desordem, no sítio ativo da enzima, além de promover ruptura nas principais ligações que estabilizam a estrutura nativa da proteína, comprometendo sua capacidade hidrolítica (Arroyo-Reyna \& Hernandez-Arana 1995). Isto está, igualmente, de acordo com a afirmativa de Fenema (1996), segundo a qual, se por um lado o emprego de temperaturas mais elevadas aumenta o rendimento das reações enzimáticas, por outro, pode provocar a inativação da enzima, comprometendo o processo de hidrólise. Estes resultados também estão de acordo com Loosen et al. (1991) e Chataud et al. (1988), que defendem o emprego de temperaturas médias $\left(50^{\circ} \mathrm{C}\right)$ no preparo de hidrolisados subtilisínicos de caseína. Segundo estes autores, este procedimento pode, ainda, contribuir para a redução do tempo de hidrólise, sem provocar significativa desnaturação da enzima, além de minimizar a contaminação microbiana.

Não foram encontrados, na literatura, trabalhos abordando o efeito da temperatura da reação sobre o perfil peptídico dos hidrolisados proteicos da farinha de trigo ou de outros cereais.

A influência da relação E:S sobre o perfil peptídico dos hidrolisados proteicos da farinha de trigo pode ser avaliada comparando-se os hidrolisados H7, H8 e H5, para os quais empregou-se E:S, para a pancreatina, de 2:100, 3:100 e 4:100, respectivamente. A vantagem do emprego de uma menor relação $\mathrm{E}: \mathrm{S}$ não foi observada em nenhum dos dois casos, ao se comparar 2:100 com 3:100 e $3: 100$ com $4: 100$, pois, além de não ter alterado, significativamente, os teores de di-tripeptídeos e de aminoácidos livres, elevou os teores de grandes peptídeos (Tabela 2). Na verdade, apesar das pequenas diferenças observadas nos perfis peptídicos, estes resultados eram esperados, teoricamente, pois, ao se utilizar uma maior quantidade de enzimas (maior relação E:S), intensifica-se o processo hidrolítico com produção de menores teores de grandes peptídeos. Como apresentado anteriormente, esta avaliação foi realizada apenas com estas amostras, visto que o presente trabalho representa parte de uma linha de pesquisa, cuja meta final está relacionada à obtenção de diversos alimentos com reduzido teor de fenilalanina.

Não foram encontrados, na literatura, trabalhos que avaliaram o efeito de E:S sobre o perfil peptídico dos hidrolisados proteicos da farinha de trigo. Apenas um estudo foi feito com arroz em grãos, no laboratório onde se desenvolveu o presente trabalho, empregando-se duas pancreatinas, a Corolase PP utilizada no presente trabalho e a P-1500 da Sigma. No primeiro caso, foi observado que o emprego da menor relação E:S (1:100), em comparação à E:S de 2:100, foi favorável para o perfil peptídico, pois contribuiu para a obtenção de maior teor de di-tripeptídeos (31,6\% e 20,6\%, respectivamente) e menor conteúdo de grandes peptídeos $(15,2 \%$ e $20,2 \%$, respectivamente), apesar de ter sido encontrado menor conteúdo de aminoácidos livres (20\% e 22\%, respectivamente) (Lopes et al. 2008), sendo estes resultados contrários aos obtidos no presente trabalho, empregando-se a mesma enzima proteolítica.

Entretanto, ao se utilizar a outra pancreatina, não foi observada, assim como no presente trabalho, vantagem do emprego de uma menor relação E:S, ao se comparar 1:100 com 2:100, pois, neste caso, obteve-se menor teor de di-tripeptídeos (14,7\% e 22,2\%, respectivamente) e maior teor de grandes peptídeos $(33,7 \%$ e $24,6 \%$, respectivamente), apesar de ter promovido, também, redução nos teores de aminoácidos livres (33,4\% e $24,2 \%$, respectivamente).

Neste estudo, compararam-se os resultados obtidos para os hidrolisados H8 (sem tratamento) e H9 (emprego de ultraturrax). O emprego do ultraturrax não exerceu qualquer influência sobre o perfil peptídico do hidrolisado proteico da farinha de trigo, visto que não foram observadas diferenças significativas para as frações F1, F3 e F4 (20,17\% e $18,47 \%, 14,82 \%$ e $15,95 \%$ e $34,18 \%$ e $35,22 \%$, respectivamente) (Tabela 2 ).

\section{CONCLUSÃO}

A associação sucessiva de uma pancreatina comercial com o extrato enzimático bruto da casca de abacaxi (EB) foi eficiente na obtenção de hidrolisados proteicos de farinha de trigo de elevado valor nutricional. Com exceção do tratamento físico da amostra, a ordem de adição das enzimas, a relação E:S e a temperatura de reação afetaram o perfil peptídico dos hidrolisados. 


\section{REFERÊNCIAS}

AFONSO, W. O. et al. Use of enzymatic hydrolysis using subtilisin for increasing the nutritional value of whey. Nutrire: Revista da Sociedade Brasileira de Alimentação e Nutrição, São Paulo, v. 34, n. 1, p. 97-114, 2009.

AFONSO, W. O. et al. Utilização do soro de leite visando reduzir a poluição ambiental: hidrólise pela pancreatina. Tecno-Lógica, Santa Cruz do Sul, v. 12, n. 2, p. 7-16, 2008.

AKIYAMA, H. et al. Profile analysis and immunoglobulin and reactivity of wheat protein hydrolysates. International Archives of Allergy and Immunology, Basel, v. 140, n. 1, p. 36-42, 2006.

ARROYO-REYNA, A.; HERNÁNDEZ-ARANA, A. The thermal denaturation of stem bromelain is consistent with an irreversible two-state model. Biochimica et Biophysica Acta, Amsterdam, v. 1248, n. 2, p. 123-128, 1995.

BIASUTTI, E. A. R. et al. Obtenção de hidrolisados do soro de leite com alto teor de oligopeptídeos utilizandose subtilisina. Brazilian Journal of Food Technology, Campinas, v. 10, n. 4, p. 226-232, 2007.

BIASUTTI, E. A. R. et al. Ação da pancreatina na obtenção de hidrolisados proteicos de soro de leite com elevado teor de oligopeptídeos. Revista Brasileira de Ciências Farmacêuticas, São Paulo, v. 44, n. 1, p. 51-60, 2008.

BORDES, J. et al. Agronomic characteristics, grain quality and flour rheology of 372 bread wheats in a worldwide core collection. Journal of Cereal Science, Amsterdam, v. 48, n. 3, p. 569-579, 2008.

BOZA, J. J. et al. Protein hydrolysate vs. free amino acidbased diets on the nutritional recovery of the starved rat. European Journal of Nutrition, Steinkopff, v. 39, n. 6, p. $237-243,2000$.

CAPOBIANGO, M. et al. Optimization of enzyme assisted processes for extracting and hydrolysing corn proteins aiming phenylalanine removal. International Journal of Food Engineering, Oxford, v. 3, n. 6, p. 1-19, 2007.

CARREIRA, R. L. et al. Analysis of peptide profile of casein hydrolysates prepared with pepsin, trypsin and subtilisin. Acta Farmaceutica Bonaerense, Buenos Aires, v. 23, n. 1, p. 17-25, 2004.

CARREIRA, R. L. et al. Efeito da remoção de fenilalanina sobre o perfil peptídico de hidrolisados proteicos da farinha de trigo. Revista do Instituto Adolfo Lutz, São Paulo, v. 69, n. 3, p. 371-378, 2010.

CHATAUD, J.; DESREUMEUX, S.; CARTWRIGHT, T. Procédé de fabrication d'un hydrolysat enzymatique de protéines riche en di- et tri-peptides, utilisable notamment en nutrition artificielle et en dietétique. FR87402837.6, 14 dez. 1987, 20 jul. 1988.
FENEMA, O. R. Food chemistry. 3. ed. New York: Marcel Dekker, 1996.

FREITAS, O. et al. Characterization of protein hydrolysates prepared for enteral nutrition. Journal of Agricultural and Food Chemistry, Washington, DC, v. 41, n. 9, p. 14321438, 1993.

FRENHANI, P. B.; BURINI, R. B. Mecanismos de absorção de aminoácidos e oligopeptídeos. Arquivos de Gastroenterologia, São Paulo, v. 36, n. 4, p. 227-237, 1999.

FRØKJAER, S. Use of hydrolysates for protein supplementation. Food Technology, Oxford, v. 48, n.10, p. 86-88, 1994.

GOLOVCHENKO, N.; KATAEVA, I. A.; AKIMENKO, $\mathrm{V}$. K. Analysis of $\mathrm{pH}$-dependent protein interactions with gel filtration medium. Journal of Chromatography, Amsterdam, v. 591, n. 4, p. 121-128, 1992.

GONZÁLEZ-TELLO, P. et al. Enzymatic hydrolysis of whey proteins: II. Molecular - weight range. Biotechnology and Bioengineering, Malden, v. 44, n. 4, p. 529-532, 1994.

GRIMBLE, G. K. et al. Effect of peptide chain length on amino acid and nitrogen absorption from two lactoalbumin hydrolysates in the normal human jejunum. Clinical Science, Portland, v. 71, n. 1, p. 65-69, 1986.

ITO, S. et al. Capillary high-performance liquid chromatography/electrospray ion trap time-of-flight mass spectrometry using a novel nanoflow gradient generator. Journal of Chromatography A, Amsterdam, v. 1090, n. 1, p. 178-183, 2005.

JE, J. Y. et al. Purification and characterization of an antioxidant peptide obtained from tuna backbone protein by enzymatic hydrolysis. Process Biochemistry, Amsterdam, v. 42, n. 5, p. 840-846, 2007.

KAMMOUN, R.; BEJAR, S.; ELLOUZ, R. Protein size distribution and inhibitory effect of wheat hydrolysates on Neutrases. Bioresource Technology, Fayetteville, v. 90, n. 3, p. 249-254, 2003.

KONG, X.; ZHOU, H.; QIAN, H. Enzymatic hydrolysis of wheat gluten by proteases and properties of the resulting hydrolysates. Food Chemistry, Oxford, v. 102, n. 3, p. 759763, 2007.

LEMIEUX, L. et al. Study of the efficiency of a mobile phase used in size-exclusion HPLC for the separation of peptides from a casein hydrolysate according to their hydrodynamic volume. Chromatographia, Wiesbaden, v. 32, n. 11-12, p. 499-504, 1991.

LI-JUN, L.; CHUAN-HE, Z.; ZHENG, Z. Analyzing molecular weight distribution of whey protein hydrolysates. Food and Bioproducts Processing, London, v. 86, n. 1, p. 1-6, 2008. 
LOOSEN, P. C. et al. Procede pour preparer um hydrolysat enzymatique. Tessenderlo Cheemie n. v. [BE/ $\mathrm{BE}$; Stationsstraat, B-3980 Tessenderlo (BE). FR-PCT/ BE91/00001, 11 jan. 1991, 25 jul. 1991.

LOPES, D. C. F.; DELVIVO, F. M.; SILVESTRE, M. P. C. Hydrolysates of skim milk powder: peptide profiles for dietetic purposes. British Food Journal, Londres, v. 107, n. 1, p. 42-53, 2005.

LOPES, D. C. F. et al. Phenylalanine removal from whey hydrolysates. Journal of Food Technology, Oxford, v. 5, n. 2, p. 191-197, 2007.

LOPES, D. C. F. et al. Removal of phenylalanine from protein hydrolysates prepared with rice. Journal of Food Technology, Oxford, v. 6, n. 2, p. 57-65, 2008.

MANU, B. T.; RAO, U. J. S. P. Influence of size distribution of proteins, thiol and disulfide content in whole wheat flour on rheological and chapati texture of Indian wheat varieties. Food Chemistry, Oxford, v. 110, n. 1, p. $88-95,2008$.

McCALLEY, D. V. Effect of buffer on peak shape of peptides in reversed-phase high performance liquid chromatography. Journal of Chromatography A, Amsterdam, v. 1038, n. 1, p. 77-84, 2004.

MIRANDA, M. Z.; EL-DASH, A. Farinha integral de trigo germinado: 3. Características nutricionais e estabilidade ao armazenamento. Ciência e Tecnologia de Alimentos, Campinas, v. 22, n. 3, p. 216-223, 2002.

MORAIS, H. A. et al. Casein hydrolysates using papain: peptide profile and encapsulation in liposomes. Acta Alimentaria, Budapeste, v. 34, n. 1, p. 59-69, 2005.

MORATO, A. F. et al. Optimization of casein hydrolysis for obtaining high contents of small peptides: use of subtilisin and trypsin. Journal of Food Composition and Analysis, Roma, v. 13, n. 5, p. 843-857, 2000.

NOGUEIRA, R.; LÄMMERHOFER, M.; LINDNER, W. Alternative high-performance liquid chromatographic peptide separation and purification concept using a new mixed-mode reversed-phase/weak anion-exchange type stationary phase. Journal of Chromatography A, Amsterdam, v. 1089, n. 1, p. 158-169, 2005.

ORTOLAN, F. Genótipos de trigo do Paraná - safra 2004: caracterização e fatores relacionados à alteração de cor de farinha. 2006. 140 f. Dissertação (Mestrado em Ciência e Tecnologia dos Alimentos)-Centro de Ciências Rurais, Universidade Federal de Santa Maria, Santa Maria, 2006.

PIMENTEL-GOMES, F. Curso de estatística experimental. 14. ed. Piracicaba: Nobel, 2000.

RÉRAT, A. A. Nutritional supply of proteins and absorption of their hydrolysis products: consequences on metabolism. Proceedings of the Nutrition Society, Cambridge, v. 52, n. 1, p. 335-344, 1993.
ROSSI, D. M. Utilização de carne mecanicamente separada de frango para produção de um hidrolisado proteico a partir de enzimas microbianas. 2007. 103 f. Dissertação (Mestrado em Microbiologia Agrícola e do Ambiente)-Faculdade de Agronomia, Universidade Federal do Rio Grande do Sul, Porto Alegre, 2007.

SAINT-SAUVEUR, D. et al. Immunomodulating properties of a whey protein isolate, its enzymatic digest and peptide fractions. International Dairy Journal, Oxford, v. 18, n. 3, p. 260-270, 2008.

SAYASLAN, A.; SEIB, P. A.; CHUNG, O. K. Wetmilling properties of waxy wheat flours by two laboratory methods. Journal of Food Engineering, Oxford, v. 72, n. 2, p. 167-178, 2006.

SILVA, V. D. M. et al. Preparation of low-phenylalanine whey hydrolysates, using papain and pancreatin immobilized on activated carbon and alumina. American Journal of Food Technology, New York, v. 2, n. 5, p. $327-$ 341, 2007.

SILVESTRE, M. P. C.; HAMON, M.; YVON, M. Analyses of protein hydrolysates: 1. Use of poly (2-hydroxyethyl-aspartamide)-silica column in sizeexclusion chromatography for the fractionation of casein hidrolysates. Journal of Agricultural and Food Chemistry, Washington, DC, v. 42, n. 3, p. 2778-2782, 1994a.

SILVESTRE, M. P. C.; HAMON, M.; YVON, M. Analyses of protein hydrolysates: 2. Characterization of casein hydrolysates by a rapid peptide quantification method. Journal of Agricultural and Food Chemistry, Washington, DC, v. 42, n. 3, p. 2783-2789, 1994 b.

SOARES, R. D. L. et al. Preparation of enzymatic skim milk hydrolysates with low phenylalanine content. Acta Farmaceutica Bonaerense, Buenos Aires, v. 25, n. 3, p. 325-332, 2006.

SOARES, R. D. L. et al. Enzyme-catalyzed production of oligopeptides from skim milk. Food Biotechnology, New York, v. 21, n. 1, p. 45-56, 2007.

SOUZA, M. W. S. et al. Obtaining oligopeptides from whey: use of subtilisin and pancreatin. American Journal of Food Technology, New York, v. 3, n. 5, p. 315-324, 2008.

VISSER, S.; SLAGEN, C. J.; ROBBEN, A. J. P. M. Determination of molecular mass distributions of whey protein hydrolysates by high-performance sizeexclusion chromatography. Journal of Chromatography, Amesterdam, v. 599, n. 1, p. 205-209, 1992.

WANG, J.; ZHAO, M.; JIANG, Y. Effects of wheat gluten hydrolysate and its ultrafiltration fractions on dough properties and bread quality. Food Technology and Biotechnology, Zagreb, v. 45, n. 4, p. 410-414, 2007. 